Okajimas Fol. anat. jap., 54 : 25-60, 1977

\title{
Some Observations on the Fine Structure of Lamprey Liver as Revealed by Electron Microscopy
}

\author{
By \\ Young Chul Shin* \\ Department of Anatomy, Faculty of Medicine, University of Tokyo \\ -Received for Publication, September 22, 1976-

\section{Introduction}

The structure of the liver has been extensively studied by many investigators both at the light and electron microscopic levels (Novikoff and Essner; '60, Bruni and Porter; '65, Novikoff and Holtzman; 70). Most of these studies, however, were carried out by using mammals as experimental animals and only limited informations on the lamprey liver were available from the electron microscopic studies by several investigators. In "the Biology of Lamprey" edited by Hardistry and Pottor ('72), structures of various organs of this animal were described in details, but those of liver were briefly reported.

In the present study, we used ammocoetes and adult lampreys, nonparasitic forms, as experimental animals. The characteristic feature in the life cycle of these animals is the transformation of some organs including the liver in the adult lamprey undergoing metamorphosis, which is immediately followed by the fasting period (Hardistry and Pottor; '71).

Therefore, the present study was undertaken to detect the morphological significance of some constituents of the liver as well as the cytoplasmic constituents of its cells through the lampreys, whose livers showed some different functional states between ammocoetes and adult lampreys.

\section{Materials and Methods}

Livers of ammocoetes and adult lampreys (Lampetra japonica) showing two different (early and later) stages of metamorphosis were studied. Tissues were fixed in $2.5 \%$ paraformaldehyde and $3 \%$ glutaral-

* On leave of absence from the Department of Anatomy, Medical College, Korea University, Seoul. 
dehyde mixture in $0.2 \mathrm{M}$ cacodylate buffer followed by postfixation with $1 \%$ osmium tetroxide dissolved in $0.2 \mathrm{M}$ cacodylate buffer.

Of these tissues, some were stained with $1 \%$ uranyl acetate in water for two hours prior to dehydration. Some tissues were merely fixed with $1 \%$ osmium tetroxide.

For the study of enzyme (acid phosphatase and peroxidase) activities, tissues were fixed in the mixture of $3 \%$ paraformaldehyde and $2 \%$ glutaraldehyde in 0.2 M cacodylate buffer, $\mathrm{pH}$ 7.3. After several changes in the same buffer, the tissues chopped as $50 \mu \mathrm{m}$ thick with Sorvall tissue sectioner (TC-2). The chopped tissues were incubated at $39^{\circ} \mathrm{C}$ in an incubation medium for acid phosphatase (Etherton and Bothem; '70) or in DAB medium for peroxidase (Fahimi; '70). The $\mathrm{pH}$ of the incubation medium for the latter was varied as 5.0,7.0 and 8.5 respectively. The postfixation was carried out for 60 minutes in $1 \%$ osmium tetroxide.

All of these tissues including the chopped ones used for the cytochemical purpose was dehydrated in a graded series of ethanol and embedded in Epon mixture. Tissues were cut on a Porter-Blum Sorvall MT-2 ultra-microtome and were stained with uranyl acetate and lead citrate. A Hitachi HU-11DS electron microscope was used for the observation.

\section{Observations}

\section{Ammocoetes}

Architecture of the ammocoetes liver showed no lobule formation but ramified tubular appearance, which did not anastomose with one another. The lumen of the hepatocytic tubule was bile canaliculus, which was surrounded by two or three hepatocytes in cross section (Fig. 1).

The sinusoidal space was relatively wide (Fig. 1)

The endothelial cell showed usually spindle shape in profile and contained an elongated nucleus with small nucleolus. The rough surfaced endoplasmic reticulum (RER) was poorly developed. Free ribosomes were not numerous. The majority of them were aggregated into small clusters which scattered randomly throughout the cytoplasm. The Golgi complex was small and consisted of lamellae and vesicles. Some of vesicles were coated. Large vacuoles and invaginations of the plasma membrane might contain finely granular materials but mostly empty. Mitochondria were small. Lysosomes were observed occasionally. The cytoplasmic process of the endothelial cell contained no mitochondria and Golgi complexes but small number of the RER and clusters of ribosomes. Cytoplasmic process of adjacent endothelial cells were over- 
lapped or disconnected with a gap of variable width (Fig. 2).

A Kupffer cell was larger than the endothelial cell with respect to both perikaryon and nucleus. The ultrastructure of the nucleus was not so different between these cells. The ultrastructure of the Kupffer cell cytoplasm, however, was more complex as compared with that of the endothelial cell. The RER and free ribosomes were less numerous. The Golgi complex consisted mainly of lamellae, vacuoles and vesicles. Mitochondria were more numerous. Various sized and shaped dense bodies, considered as lysosomes, were usually observed.

The perisinusoidal space contained similar structures as those seen in the mammalian liver. Of these structures, collagenous fibrils were relatively abundant and oriented in various directions. The basement lamina was two in number (Fig. 2). One beneath the endothelial cell was indistinct and discontinuous. The other enveloping the hepatocytic surface facing the space of Disse was distinct and continuous. It made infoldings between adjacent hepatocytic tubules. Structures, contained usually in the perisinusoidal space, were recognized even in the deep portion between adjacent hepatocytic tubules.

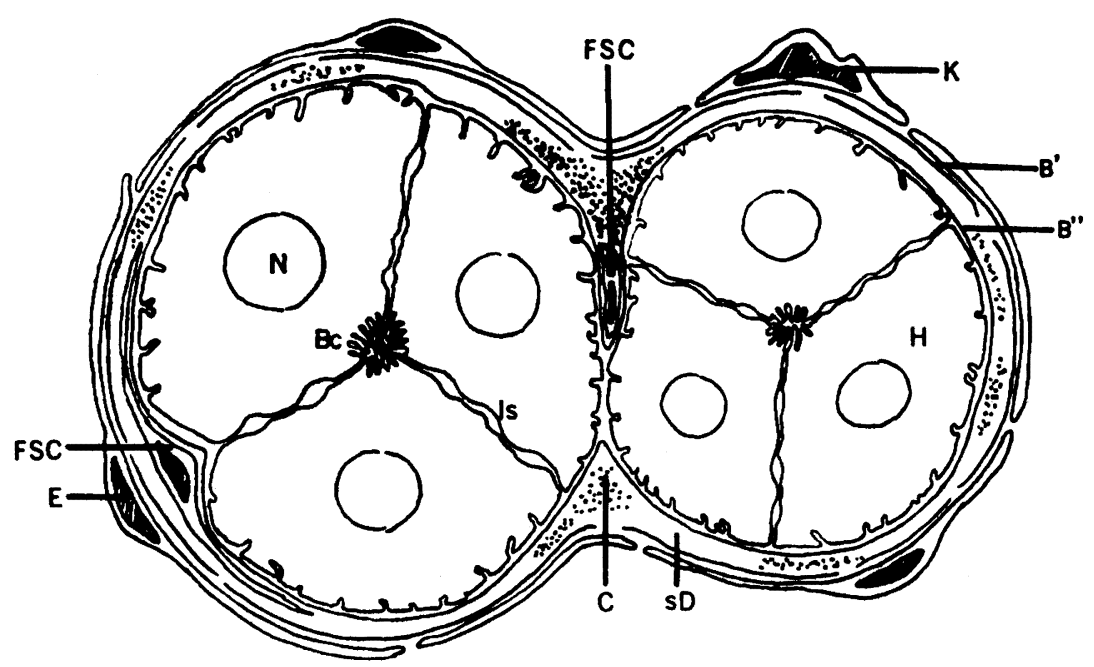

The schematic diagram of the ammocoetes hepatocytic tubules which completely surrounded by the basement lamina $\left(\mathrm{B}^{\prime \prime}\right)$. The infolding of the basement lamina between adjacent hepatocytic tubules contain fat storing cell (FSC) and collagenous fibrils $(C)$. The other basement lamina $\left(B^{\prime}\right)$ beneath the endothelial cells $(\mathrm{E})$ is discontinuous. $\mathrm{H}$ : hepatocyte. $\mathrm{N}$ : nucleus. $\mathrm{Bc}$ : bile canaliculus. Is : intercellular space. $\mathrm{K}$ : Kupffer cell. $\mathrm{sD}$ : space of Disse.

A fat storing cell was usually situated in the recess between adjacent hepatocytes which were surrounded by the distinct basement lamina. This cell showed spindle or triangular shape. In cross section, 
it appeared round or triangular in shape. The nucleus was elongated or oval in shape. The nuclear envelope showed occasional indentation, induced by the cytoplasmic lipid droplet. Chromatin materials were accumulated in various sizes and shapes along the nuclear envelope. The nucleolus was also observed. The RER showed some parallel cisternae but most of them were scattered randomly throughout the cytoplasm. The Golgi complex consisted of lamellae, vacuoles and vesicles.

Vacuoles and vesicles including coated ones were observed occasionally throughoht the cytoplasm. Tubules without ribosomes were scarcely identified. Mitochondria were less numerous. Lysosomes were observed infrequently. Microtubules and filaments were also observed. This cell contained usually only one lipid droplet whose surface showed occasional filamentous structure. The fat storing cell without lipid droplet, however, was also observed frequently (Fig. 1).

Hepatocyte was usually elongated and pyramidal in shape (Fig. 1).

Surface of the hepatocyte forming the bile canaliculus projected numerous microvilli, about $1 \mu \mathrm{m}$ long, into the lumen. The hepatocytes forming the bile canaliculus were joined near the lumen by the junctional complex consisting of tight and intermediate juctions, and desmosome (Fig. 4). The surface facing the intercellular space showed occasional infoldings. The intercellular space was usually saccular or elongated-tubular in profile (Fig. 1). The surface facing the space of Disse showed irregular infoldings of the plasma membrane which was larger and more numerous as compared with those on the surface facing the intercellular space.

The nucleus was round or oval in shape and consisted of fine granular nucleoplasma as showing dispersed granules of low and moderate electron densities and small clusters of high electron density throughout the karyoplasm. Dense granular areas, which had irregular outlines, disposed occasionally around the periphery, and in the center of the nucleus. The outer nuclear membrane was studded with ribosomes. The nucleolus appeared to consist of closely packed dense granules with coarse strands that branched and anastomosed.

Ribosomes appeared no identifiable pattern of arrangemnt but to be grouped frequently into clusters.

RER appeared usually in the form of parallel cisternae with dilated ends which were arranged parallel to the nuclear envelope or to the cell surface. However, the tubular or vesicular profiles studded with ribosomes were also observed. The materials contained in the RER were flocculent and of low electron density.

Tubules without ribosomes were scarcely distributed throughout the cytoplasm beyond the periphery where they were observed frequently. They also contained flocculent materials of low electron den- 
sity as seen in the RER.

Golgi complexes were frequently observed near the bile canaliculus and in the perinuclear area. They consisted usually of several parallel cisternae with dilated ends, vacuoles and vesicles. Some vacuoles and vesicles appeared in the process of separation from the cisternae. Detached vacuoles and small vesicles including coated ones were observed not only in the vicinity of the Golgi complex but also near the cell surfaces facing the intercellular space or the space of Disse. Containing materials in the Golgi complex showed three distinct types of morphological features. The first type, which was observed in parallel cisternae with dilated ends and small vesicles, was flocculent materials of low electron density. The second type was in the form of fine granules of moderate electron density. The third was closely packed but not discreted materials of high electron density (Fig. 5). The Golgi vacuoles might be classified into two types according to their contents that belong to one of the latter two types of containing materials mentioned above. The materials identical to those, contained in both types of vacuoles, were observed in the intercellular space and the space of Disse. No vacuoles, however, were observed on the surface facing the bile canaliculus.

Mitochondria were numerous. Most of them were usually arranged peripherally to complexes of the RER cisternae. The profile of mitochondria showed the main shapes which were round and oblong. Cristae were tubular or vesicular in appearance. Intramitochondrial granules were observed in the matrix.

Lysosomes were numerous and distinctly appeared to converge on the cytoplasmic bordering on the bile canaliculus (Fig. 1, 4). Lysosomes varied in size and shape. Many of them consisted of dense and homogeneous materials. Some showed a superficial lamellar layer with less dense but homogeneous inner core.

\section{Adult lamprey in the early stage of metamorphosis (early adult lamprey).}

Architecture showed no intercellular, perisinusoidal and sinusoidal spaces, and bile canaliculus. Hepatocytes were closely apposed each other, and their surfaces were usually straight. The individual hepatocyte was quadriangular or polyangular in shape (Fig. 6). Various structures as seen in the perisinusoidal and sinusoidal spaces of the ammocoetes and occasional remnants of microvilli were observed in the clefts between apposed hepatocytes.

Nucleus was round or oval in shape and consisted of the fine granular nucleoplasm as seen in that of the ammocoetes. However, the slight increase of granules and their small clusters of moderate or 
high electron density was occasionally observed with an increase of dense granular areas of chromatin masses. The space of nuclear envelope was dilated as seen in the RER.

Ribosomes showed similar distribution to those of the ammocoetes.

RER appeared in the form of parallel cisternae, which were rondomly distributed throughout the cytoplasm. Most of them were highly dilated. Limiting membranes of some RER were studded with only a few ribosomes. Containing materials in the RER showed two distinct types of morphologic features. The first type was in the from of flocculent materials of low or moderate electron density. The second type was of granules of high electron density. These granules were 200-500 $\AA$ in diameter. These two different materials might be associated with each other in single cisternae.

Tubules without ribosomes appeared largely in the immediate vicinity of the Golgi complexes but were distributed scarcely throughout the cytoplasm. Containing materials in the tubules without ribosomes showed two distinct types of morphological features. One of them was flocculent materials of low electron density. The other was in the form of granules of high electron density. These granules were 200-500 $\AA$ in diameter. Most of the tubules in the vicinity of the Golgi complexes contained granules, which appeared singly, clustered or as a row. These two different materials might appear simultaneously in a same tubule (Fig. 6, 7).

The Golgi complexes consisted usually of dilated cisternae and a great number of small vesicles, some of them were coated ones. Small vesicles were occasionally in the form of aggregation in the vicinity of the Golgi complexes. Some of these vesicles were in the direct communication with cisternae. Large vacuoles, however, were extremely rare. Containing materials in the Golgi complexes showed two distinct types of morphologic features. One of them was flocculent materials of moderate density which was observed in small vesicles or flattened cisternae. The other was in the form of granules of high electron density which was observed in the ends of flattened cisternae and occasional vacuoles. Granules were also observed in the cleft between or in the infolding of the plasma membrane. These granules were 200-500 $\AA$ in diameter. Dilated cisternae were mostly empty.

The third vacuoles were occasionally observed. A limiting membrane of vacuoles were somewhat thickened. They contained flocculent materials of moderate electron density (Fig. 7).

Mitochondria were usually in the periphery of the hepatocyte. The population of them was somewhat decreased. No morphologic changes were observed.

Lysosomes were usually observed in the vicinity of the Golgi complex. The population of them showed a decrease. They consisted of 
homogeneous materials, many of them were mottled with granular materials of high electron density (Fig. 7).

\section{Adult lamprey in the late stage of metamorphosis (late adult lamprey).}

Architecture showed interspaces between hepatocytes. No bile canaliculi were also observed (Fig. 8).

Sinusoidal and perisinusoidal spaces occured again with the reappearance of interspaces between hepatocytes. All of the structures, which were usually observed in the spaces of the ammocoetes liver, appeared again at their usual position. Both basement laminas in the space of Disse remained intact. Endothelial and Kupffer cells showed no specific changes but for the diminution of vesicles and vacuoles.

Fat storing cell showed some changes to compared with that of the ammocoetes. The number of the lipid droplet was highly increased. Tubular RER and small vesicles showed an increase in the vicinity of the Golgi complex. All of the membrane-limited structures in the cytoplasm of this cell were dilated and filled with flocculent materials of low or moderate density (Fig. 9).

Surfaces of hepatocytes showed marked irregularities. Adjacent hepatocytes were connected frequently through gap junctions (Fig. 10). Vesicles and vacuoles near the surface of the hepatocyte were highly diminished to compared with those on the hepatocytic surface of the ammocoetes.

A nucleus of the most hepatocytes was irregular in shape. There was a marked increase of chromatin blocks with granular clusters of moderate or high electron density throughout the karyoplasm. No dilated space of the nuclear envelope was observed. The outer envelope was also studded with ribosomes.

Ribosomes were highly decreased to compared with those in early adult lampreys.

RER (Fig. 11, 12) appeared also in the form of cisternae, tubules or vesicles which were decreased in amount as compared with those of early adult lampreys. These membrane limited structure were randomly distributed throughout the cytoplasm, except for some cisternae showing parallel arrays. Containing materials in the RER showed two distinct types of morphologic features. One of them was flocculent materials of low electron density. The other was in the form of granules of moderate or high electron density. These granules were $700-1000 \AA$ in diameter. The granules appeared within the cisternae, tubules or vesicles whose limiting membranes were studded with only a few ribosomes (Fig. 11).

Tubules without ribosomes appeared more frequently and to be 
grouped in the vicinity of the Golgi complexes. Containing materials in these tubules showed three distinct types of morphologic features. The first type was flocculent materials of low electron density. The second type was in the form of granules of moderate or high electron density. These two types of containing materials were often associated with each other in the same tubules or vesicles. In some cases, the granules lost their discrete contours and became amorphous. The third type was amorphous materials of moderate or high electron density. This type of containing materials was observed in the cisternal elements showing a feature characteristic of the RER, which was studded with a few ribosomes; or the smooth surface endoplasmic reticulum (SER). These materials appeared in various sizes (Fig. 13, 14, 15). The largest of them were reached to $1-1.5 \mu \mathrm{m}$ in diameter and their contents were similar to those of lipid droplets (Fig. 15).

The Golgi complexes (Fig. 11, 12) showed elongated or encircled parallel cisternae. Many of them were gradually transformed into the whorl-like shape. Vacuoles, considered to be detached from cisternae, showed lysosomal impressions due to their amorphous contents. Small vesicles showed a decrease. Containing materials showed three distinct types of morphologic features. One of them was flocculent materials of moderate electron density. They were observed in the dilated ends of the cisternae. The other type was in the forms of granules and amorphous materials of high electron density. These two types of materials were associated with each other in the dilated ends of the cisternae or detached vacuoles.

The third vacuoles were also observed as seen in the early adult lamprey hepatocytes.

Mitochondria were also observed in the periphery of the hepatocytes. The population of them was more decreased. Profiles of mitochondria were pleomorphic. Some of them were closely contacted with the surface of lipid droplets. Intramitochondrial granules showed a marked decrease.

Lysosomes were usually observed in the vicinity of the Golgi complexes. All of them were mottled with granular materials of high electron density.

\section{Cytochemistry.}

Cytochemical studies were carried out to the structures which were recognized as lysosomes from the morphological criteria.

Some of the structures in both ammocoetes and adult lamprey hepatocytes showed no positive reaction for acid phosphatase (Fig. 16). No reactive products were also observed on the myelin figure of the structures. No difference in the reactive products were observed be- 
tween structures of both ammocoetes and adult lamprey hepatocytes.

Most of the structures identified as lysosomes showed positive reaction for peroxidase in both ammocoetes and adult lamprey hepatocytes (Fig. 17). At pH 7.3 and 8.5 of incubation media, the intensity of the staining in the structures did not change appreciably. At $\mathrm{pH}$ 5.0, however, the staining appeared quite weak. No appreciable difference of reaction appeared between these structures of ammocoetes and adult lamprey hepatocytes. No structures such as microbodies showing a positive reaction for the peroxidase were demonstrated in these experimental animals, although the peroxidase activity was demonstrated in the microbodies of the mouse liver processed by the same technique.

\section{Discussion}

In the following points the structure of the ammocoetes liver is different from that of mammalian liver. The first differences is a presence of two basement laminas in the space of Disse. The second is a presence of the relatively wide sinusoidal space. The third is an appearance of irregular infoldings of the plasma membrane of the hepatocytic surface facing the space of Disse. The fourth is an appearance of the relatively wide intercellular space between adjacent hepatocytes. The fifth is a presence of the large bile canaliculi with numerous long microvilli. The last is an appearance of the intracellular membrane system which appeared well developed as compared with those of mammalian hepatocytes.

Above-cited facts certainly indicate that the hepatocyte of the ammocoetes liver was in the state of active function.

Sinusoidal linings and their basement laminas have been studied by many investigators (Wisse; '70, Grubb; '71). In young calves, Wood ('63) has observed that the sinusoid had a continuous endothelium, which was surrounded by a basement lamina. Gemmel and Heath ('71) have observed a discontinuous endothelium surrounded by a basement lamina. Fawcett ('55), and Schaffner and Popper ('63), who studied on the human and rat livers, observed that the endothelial lining was discontinuous and lack of basement lamina. The endothelial lining of the sinusoid and the basement lamina have been reported not only in the different species (Kuhn and Oliver; '65) but also in various states of the liver (Stenger; '66, Karrer; '61, Burkel and Low ; '66). In the present study, the sinusoid of the ammocoetes liver was surrounded by a poorly developed basement lamina. There was another well developed basement lamina which surrounded completely the hepatocytic tubule. These basement laminas were well preserved even in the adult lamprey liver undergoing metamorphosis. The significance of the base- 
ment lamina is not clarfied as yet. Heath and Wissig ('66), and Karnovsky ('68) have described that large molecules could readily gain access to the space of Disse in animals of no basement lamina around the sinusoid. Roessle ('30) has described that the alteration of the space of Disse is functionally signifiant in the nutrition of the liver parenchyme. In mammals, the space of Disse is arranged for rapid interchange between blood stream and hepatocytes. In animals examined in the present study, the double basement laminas probably act as diffusion barriers to prevent the hepatocytes from over exposure into the plasma components of wide sinusoidal space. Moreover, the absence of microvilli of the hepatocytes and the presence of various structures such as abundant collagenous fibrils and subendothelial processes of fat storing cells in the space of Disse may cause less exchanges.

Since Ito's discovery of the fat storing cell, many investigators (Yamagishi ; '59, Ito and Shibasaki ; '68, Ito; '73) have discussed how lipid droplets formed in the fat storing cell. The morphologic expression of the mechanism for the lipid synthesis in the fat storing cell, however, is not clarified as yet. Several investigators (Satsuki; '55, Satsuki et al.; '56) have described that the lipid stored in the fat storing cell may be supplied to the hepatocyte. Ito and Shibasaki ('65) has postulated that pinocytotic vesicles contain ingested probable precursors such as fatty acid and they may migrate to the Golgi complex as adipose tissue does. Kobayashi and Takahashi ('71) have observed the increased lipid droplets and enlarged Golgi complexes in hepatocytes of rats, given excessive dose of vitamin A. Hirosawa and Yamada ('73) have observed the presence of vitamin A in the fat storing cell with electron microscope autoradiography. In the present study, the fat storing cell of the ammocoetes liver contained usually none or only one lipid droplet. In the late adult lamprey, however, the number of lipid droplets stored in the fat storing cell increased markedly and was usually reached to ten in maximum. The Golgi lamellae, vesicles and vacuoles, and cisternae or tubules with ribosomes showed an increase, and were dilated and filled with flocculent materials. No phagosomes but few lysosomes were observed in the fat storing cell as Bronfenmajer, Schaffner and Popper ('66) have reported. From the fact that the findings mentioned above appeared at the time when the mobilization of fatty acids increased, it may be thought that the lipid synthesis may occur in the fat storing cell and the lipid is stored as a droplet in its cytoplasm.

In the present study, we did not detect the presence of vitamin A in the lipid droplet of the fat storing cell. This cell, however, showed many cisternae or tubules with ribosomes especially in the adult lamprey. The above fact seemed to indicate that the fat storing cell was in the stage of active protein synthesis to make the lipoprotein with 
mobilized lipid element. The same result may be obtained from vitamin A which needs protein to combine (Smith et al.; '73). Therefore, it may be suggested that vitamin A was also stored within the lipid droplet in the fat storing cell of the lamprey liver as Hirosawa and Yamada have observed it in the mouse liver.

Junctions between adjacent cells have been studied by many investigators (Chalcroft and Bullivant; '70, Goodenough and Stockenius ; '72, Peracchia; '73). The cell membrane, in general, has many different functions which are located in differentiated functional sites (Muir; '67). In the ammocoetes liver, junctional complexes were observed frequently on any side of bile canaliculi. These junctional complexes disappeared with losing of bile canaliculi in the adult lamprey. Gap junctions were observed occasionally in maculae as along the boundaries of adjacent hepatocytes in the ammocoetes liver. These gap junctions increased markedly in the adult lamprey. It is not known, however, why these gap junctions increased in the adult lamprey. Goodennough and Revel ('70) have observed that the Lanthanum freely penetrates through gap junctions. They have concluded that gap junctions are the sites of electron couplings between hepatocytes in the mouse liver. Payton, Bennett and Pappas ('67), Goshima ('70), Goodennough and Gevel ('71) and Gilula, Reeves and Steinbach ('72) have reported that the gap junction is believed to be the site of intercellular passage of ions and small molecules. From the fact cited above, it is probable that no special differentiation of the plasma membrane was needed for the permeability of materials in the ammocoetes liver whose hepatocytes could be freely contacted with plasma components through the wide intercellular spaces. However, the liver of the early adult lamprey lost their intercellular spaces due to close apposition of hepatocytes. Therefore, an increase of gap junctions in the adult lamprey seems to be resulted from that the early adult lamprey may have needed intercellular passages for ions and small molecules. Gap junctions seem to have been the sites of remarkable resistance to the mechanical forces in the late adult lamprey whose hepatocytes were in the process of separation. Therefore, it may be thought that the junctional membranes were firmly attached each other.

Even with various studies to detect the mode of the bile secretion, the morphologic expression on the bile secretion has not been conclusively demonstrated. Essner and Novikoff ('60) have proposed that lysosomes are the counterparts of bile pigment containing bodies. Arias ('61) has also suggested that lysosomes in the hepatocyte may carry bilirubin under normal condition. Bruni and Porter ('65) have observed lysosomes which located within the lumen of bile canaliculi. In the present study, it was not recognized whether bile pigments were concentrated in the lysosomes or particles in the bile canaliculi 
were homologous to the secreting bile pigments. The ammocoetes showed well developed bile canaliculi containing numerous microvilli and the lysosomes were largely distributed around the bile canaliculi within which many particles similar to the lysosomal substances were contained. In the adult lamprey, however, whose bile canaliculi disappeared, less number of lysosomes appeared with restriction in the vicinity of the Golgi complex. It is evident that bile secretion could not occur due to loss of bile canaliculi in the adult lamprey. Therefore, it may be thought that bile secretion had some functional connections with lysosomes in the ammocoetes hepatocytes. Bertolini ('65) has observed an accumulation of bile products in the adult lamprey (Lampetra zanandreai) liver losing their bile canaliculi. Sterling, Merenze, Winsten and Krieger ('67) have also observed a qualitative increase of bilirubin in the adult lamprey (Petromyzon marinus) liver after losing their bile duct. In the mammalian liver in which a bile stasis occurs, investigators (Essner and Novikoff ; '60, Goldfischer et al. ; '62, Orlandi ; '62) have observed that bile pigments stored in lysosomes, which increase in number and size, were dispersed throughout the cytoplasm from their usual peribiliary localization. There were some different results between studies of ours and other investigators. In the present study, the number of lysosomes was observed to decrease and appeared in the vicinity of the Golgi complex. Ferritin-like materials were not observed in the lysosomes. It is probable that the results obtained from Petromyzon marinus and mammals may be different from those of Lampetra japonica used in the present study, possibly because of their different characters. Petromyzon marinus and mammals may maintain the function of hepatocytes, since they feed normally after losing their bile canaliculi or during bile stasis. Therefore, the accumulation of bile in their livers may be expected in these animals. The adult lamprey in the present study, however, did not feed after losing their bile canaliculi. Therefore, it may be thought that the mechanism of bile production may have been suspended with disappearance of the bile canaliculi or the lack of protein, which was able to conjugate with bilirubin, may have been resulted from a decrease of protein synthesis and an overuse of proteins which contributed to form lipoproteins with large amounts of mobilized fatty acids, since the gradual loss of the hepatocytic activity and lipid mobilization from fat depot have been occured at this stage. If these speculations are true, the accumulation of bile in the hepatocyte can not be expected, eventhough the hemolysis occured during sexual maturation followed by fasting period. It is not known, however, why such difference is resulted between adult forms of Lampetra zanandreai and japonica, notwithstanding both animals have resemble charactor showing fasting period after metamorphosis. It seems that such difference those animals 
is resulted from some probable factors such as an activity of the hepatocyte, an amount of protein and a degree of hemolysis. Lampetra zonandreai showed dark brown or deep green liver indicating huge accumulation of bile, while Lampetra japonica, used in the present study, showed yellowish liver indicating lipid infiltration which will be described later.

In the cytochemical study on the ammocoetes and adult lamprey hepatocytes, acid phosphatase activities appeared with restriction to some lysosomes. It is not known, however, whether lysosomes, which show no reactions to acid phosphatase, contain these enzymes. The lysosomes, which contain inactive forms of acid phosphatase, show no reactions to these enzymatic activities (Ogawa and Abe; '73). Therefore, some lysosomes within ammocoetes and adult lamprey hepatocytes may contain inactive forms or may not contain these enzymes. As far as the distribution of the lysosomes around the bile canaliculi in the ammocoetes hepatocytes is concerned, which of the lysosomes showing presence or absence of acid phoshatase activity may be relating to the bile secretion. In both ammocoetes and adult lamprey hepatocytes, peroxidase activity appeared also in the membrane-limited structures which were identified as lysosomes. de Duve et al. ('60) have previously reported the fact that the granules comparable to microbodies are absent in the ammocoetes hepatocytes. It is generally agreed that the micrbodies and lysosomes are two distinct cell entities morphologically (Hruban et al.; '72, Novikoff and Novikoff ; '72, Novikoff ; '73), but they have some similarities, of which both bodies are enclosed by a limiting membrane, both contains enzymes that are hydrolytic in character (Bruni and Porter; '62) and both may play a role as an intracellular digestion (Claude ; '62). Therefore, it is possible that the lysosomes may contain any enzymes along with their characteristic ones in the hepatocytes of these primitive animals, and the lysosomes showing peroxidase activity may play a similar role as the peroxidase does in other animals.

The Golgi complex is known as the site of both concentration and package of the product for export by the large vacuoles which arise by dilatation of the Golgi cisternae (Sjöstrand and Hanzon ; '54, Essner and Novikoff ; '62, Novikoff et al.; '71). The Golgi complex plays also a major role in the attachment of carbohydrate to the product (Lo and Marsh; '70). In the ammocoetes hepatocytes, two types of detached vacuoles from Golgi cisternae, one with fine granules of moderate electron density and the other with closely packed materials of high electron density. It is not known, however, why they showed different sizes and densities. They were distributed largely on the surface facing the intercellular space or the space of Disse but less on the surface facing the bile canaliculi where the large population of lysosomes were 
distributed. Clusters of particles similar to those of vacuoles were also observed in the intercellular space or the space of Disse. From the result cited above, it may be thought that both types of vacuoles contribute to tansport the product, while the lysosomes may have some functional connections in the bile secretion. The vacuoles showed a great decrease in the hepatocytes of the early adult lamprey. It is probable that a decrease of vacuoles was due to loss of intercellular space as a secretory passage at the outside of the hepatocyte. In the hepatocyte of the late adult lamprey, many of the vacuoles contained amorphous materials and they showed lysosomal impression. It seems that the findings of these vacuoles may occur as a result of any changes of the enzymatic activity or the functional depression in this site.

Small vesicles were observed besides those vacuoles in the vicinity of the Golgi cisternae. These vesicles fairly increased around the highly dilated Golgi cisternae in the hepatocytes of the early adult lamprey. Of these vesicles, some were budding from the ER to fuse with Golgi cisternae. Others, which seemed to carry acid phosphatase and presumably other lysosomal enzymes, were separating from Golgi cisternae to the large vacuoles (Novikoff and Holtzman; '70). Therefore, it may be thought that an increase of small vesicles are morphological expression of the transport for the excess amounts of the product and contribute to the digestion of the product as seen in the large vacuoles (Fig. 12) which showed lysosomal impression.

The early adult lamprey showed dilated and particle free Golgi complex as seen in the early stage of fatty livers induced by choline deficiency (Amick and Stenger, '64), orotic acid feeding (Jatlow et al.; '65) and an use of puromycin (Jones et al. ; '67). The other morphologic expression of the early adult lamprey was an appearance of granular materials in the intracellular membranes. In the studies to detect the granular materials, many investigators have emphasized that granular materials showing osmiophilia probably contain substantial amount of lipid (Park; '65, Hamilton et al. ; '66). Stein and Stein ('67), and van Golde, Fleischer and Fleischer ('71) have observed that the triglyceride contents of granules in the Golgi complex increased as compared to the corresponding granules in the SER. Glaumann et al. ('75) have described that the lipoprotein particles presumed to be precursors of very low density lipoprotein (VLDL) begins in the RER and continues in the SER. They have also observed that there is a parallel change in chemical composition and size of the lipoprotein particles as they make their way through the ER and the Golgi complex. Claude ('70) has described that the RER does not synthesize triglycerides, in contrast to the smooth counter part. van Golde, Fleischer and Fleischer ('71) have described that both rough and smooth ER take part in triglyceride synthesis. Glaumann, Bergstrand and Ericsson ('75) have described 
that the RER is the site of both protein and lipid synthesis, while the SER lacks the capability for protein synthesis. In the present study, the early adult lamprey contained two distinct forms of materials appearing in the cisternae or round vesicles, which were partly associated and partly unassociated with ribosomes. Of these materials, one, the form of flocculent materiales was similar to that found in the ammocoetes, but the other, the form of granules in high electron density was only found in the adult lamprey whose hepatocytes were laden with lipid droplets as an indication of lipid mobilization. It can be assumed that mobilized fatty acids from fat depot were being taken up by hepatocytes and they were released into the RER where they were coupled with protein, since the adult lamprey in the present study were in the fasting state. Therefore, it may be thought that the granules in the adult lamprey were lipoproteins rather than other materials, although the mobilized fatty acids bound to the proteins can not be recognized under the electron microscope (Ashworth et al.; '65). We have also observed that the granules increased in size and electron density through their way in the intracellular membranes and in the narrow cleft between adjacent hepatocytes. These granular materials, of course, may have been transported by the way of cisterane and vesicles to the Golgi complex and finally released to the outside of hepatocytes (Lo and Marsh; '70). The granules appearing in the intracellular membranes were similar to those in the narrow cleft between adjacent hepatocytes. They were probably lipoprotein particles, which have been synthesized in the hepatocytes and presented in the process of being secreted immediately prior to or during metamorphosis. The granules were also observed in the late adult lamprey. Many of the granular materials, however, have been presented in the process of accumulation as an osmiophilic amorphous contents in the ER and Golgi complex. The major expression of the late adult lamprey was an appearance of liposomes including giant ones and large cytoplasmic lipid droplets. These findings, which characterized the fatty liver seem to be advanced forms of those in the early adult lamprey, which showed small sized liposomes and lipid droplets. The lipid nature of the osmiophilic material enclosed by the limiting membrane as liposome has previousely been suggested by many investigators. Baglio and Farber ('65) have described liposomes in the liver of untreated fasting rats. Hamilton, Regan and Lequir ('66) have observed liposomes in greater number under condition of abnormal triglyceride accumulation. Schlunk and Lombardi ('67) have speculated that liposomes could occur as a result of an interference with the release of hepatic triglycerides into the plasma. The chemical analysis of the contents of liposomes showed them to consist mainly of neutral fat (Schlunk and Lombardi ; '67) or lipoprotein (Lombardi ; '65). In the present study, the liposomes especi- 
ally giant ones and lipid droplets appeared as spherical bodies containing osmiophilic materials. They showed only difference in presence or absence of the enclosing membranes. The liposome appeared as well circumscribed osmiophilic material filled in the dilated ER as Lombardi has described ('66). The enclosing membranes were studded with ribosomes which highly diminished in number and size. The gradual loss of these attached ribosomes seems due to utilization of proteins which contributed to form lipoproteins with mobilized fatty acids. The proteins may also be utilized to bind vitamin A (Smith et al.; '73) and the vitamin A binding protein may be stored in the lipid droplets of the hepatocytes as occurs in the fat storing cell, since the similarities showing dilated RER and lipid droplets appeared in both hepatocytes and fat storing cells. The origin of the liposomal membranes from the RER is strongly suggested in the present study as seen in the Figures 13, 14 and 15. From the fact mentioned above, it is speculated that the enclosing membranes of the liposomes may represent the areas of the RER membranes specialized for fatty acid and lipoprotein synthesis. The lipid droplet may be formed by an increase of osmiophilic materials from the liposome with loss of the enclosing membrane.

Many of the Golgi complex, appeared to change an organized system of membranes, contained high electron dense granules or amorphous materials. They may have been correlated with lipid accumulation. The vacuoles of the Golgi complex did not show typical ones but lysosomal impression. The role of lysosomes in the intracellular lipid metabolism has received little attention. The structures showing lysosomal impression have suggested the intracellular catabolism of lipoprotein granules which could contribute to a decrease of the rate of lipoprotein secretion. The role of lysosomes in the intracellular lipid metabolism as well as the bile metabolism, however, remains to be determined.

\section{Summary}

The several structures in the liver were studied by comparing the differences between ammocoetes (larva form) and adult lamprey (adult form).

Both of ammocoetes and adult lamprey showed double basement laminas within the space of Disse. One beneath the endothelial cell was indistinct and discontinuous. The other, which surrounded the hepatocytic surface facing the space of Disse, was distinct and continuous.

Fat storing cells in the ammocoetes liver contained usually none or only one lipid droplet within their cytoplasm. In the adult lamprey, the number of both fat storing cells and their containing lipid droplets was makedly increased, especially the number of the latter reached 
usually to ten in maximum.

Bile canaliculi disappeared in the adult lamprey. No junctional complexes on the side of the bile canaliculi were also observed in the adult lamprey.

Gap junctions between adjacent hepatocytes increased in the adult lamprey, while they were rarely observed in the ammocoetes hepatocytes.

Lysosomes appeared to converge around the bile canaliculi and in the vicinity of Golgi complexes in the ammocoetes hepatocytes. In the adult lamprey, the lysosomes could be merely observed in the vicinity of Golgi complexes. The lysosomes showed a decrease and their amorphous contents were frequently mottled with electron dense granules.

In the cytochemical studies, some of the lysosomes in the ammocoetes hepatocytes showed positive reactions for both of acid phosphatase and peroxidase but no microbodies showing reaction for peroxidase were demonstrated.

Liposomes including giant liposomes consisted of dilated ER filled with electron dense amorphous materials in the adult lamprey hepatocytes.

Many lipid droplets similar to the contents of giant liposomes were observed in the hepatocytes of the late adult lamprey, while neither lipid droplets nor liposomes were observed in the hepatocytes of the ammocoetes liver.

\section{References}

Amick, C. J. and Stenger, R.: Ultrastructural alterations in experimental acute hepatic fatty metamorphosis. Lab. Invest., 13: 128-136, 1964.

Arias, I. M.: The transport of bilirubin in the liver. In: Progress in liver disease. Popper, H. and Schaffner, F. (eds.), Grune and Stratton, New York, 187-201, 1961.

Ashworth, C.T., Leonard, J.S., Eigenbrodt, E.H. and Wrightsman, F. J.: Hepatic intracellular osmiophilic droplets. Effect of lipid solvent during tissue preparation. J. Cell Biol., 31: 301-318, 1966.

Ashworth, C.T., Wrightsman, F., Cooper, B. and Di Luzio, N.R.: Cellular aspects of ethanol induced fatty liver: a correlated ultrastructural and chemical study. J. Lipid Res., 6 : 258-268, 1965.

Baglio, C.M. and Farber, E.: Reversal by adenine of the ethionine induced lipid accumulation in the endoplasmic reticulum of the rat liver. J. Cell Biol., 27: 591-601, 1965.

Bertolini, B.: The structure of the liver cells during the life cycle of a brook lamprey. Zeitsch. f. Zellforsch., 67: 297-318, 1965.

Bronfenmajer, S., Schaffner, F. and Popper, H.: Fat storing cell (lipocytes) in human liver. Arch. Path., 82: 447-453, 1966.

Bruni, C. and Porter, K.R.: The fine structure of the parenchymal cell of the normal rat liver. Am. J. Path., 46:691-729, 1965.

Burkel, W.E. and Low, F.N.: The fine structure of rat liver sinusoids, space of Disse and associated tissus space. Am. J. Anat., 118: 769-784 1966. 
Chalcroft, J. P. and Bullivant, S.: An interpretation of liver cell membrane and junction structure based on observation of freeze-fracture replicas of both sides on the fracture. J. Cell Biol., $47: 49-50,1970$.

Claude, A.J.: Spontaneous, transplantable renal carcinoma of the mouse. Electron microscope study of the cells and of an associated virus like particle. J. Ultrastruct. Res., 6 : 1-18, 1962.

Claude, A. J.: Growth and differentiation of cytoplasmic membrane in the course of lipoprotein granule synthesis in the hepatic cell. I. Elaboration of elements of the Golgi complex. J. Cell Biol., 47: 745-766, 1970.

de Duve, C., Beaufay, H., Jacques, P., Rahman, Y., Sellinger, O.Z., Wattiaux, R. and de Coninck, S.: Intracellular localization of catalase and of some oxidase in rat liver. Biochem. Biophys. Acta. (Amst.), $40: 186-187,1960$.

DeRobertis, E. D. P., Saez, F.A. and DeRobertis, E.M.F., Jr.: The Cell Biology. 6th ed., W.S. Saunders Co., 1975.

Essner, E. and Novikoff, A.B.: Human hepatocellular pigments and lysosomes. J. Ultrastruct. Res., 3 : 374-391, 1960.

Essner, E. and Novikoff, A.B.: Cytological studies on two functional hepatomas, interrelations of endoplasmic reticulum, Golgi apparatus and lysosomes. J. Cell Biol., 15: 289-312, 1962.

Etherton, J.E. and Bothem, C.M. : Factors affecting lead capture methods for the fine localization of rat lung acid phosphatase. Histochem. J., 2: 507-519, 1970.

Fawcett, D. W.: Observations on the cytology and electron microscopy of hepatic cells. J. Nat. Cancer Inst., 15: 1475-1503, 1955.

Gemmel, R.T. and Heath, T.: Fine structure of sinusoids and portal capillaries in the liver of the adult sheep and the newborn lamb. Anat. Rec., 172:57-70, 1971.

Gilula, N.B., Reeves, O.R. and Steinbach, A.: Metabolic coupling, ionic coupling, and cell contacts. Nature (Lond.) 235: 262-265, 1972.

Glaumann, H., Berstand, A. and Ericsson, J. L. E. : Studies on the synthesis and intracellular transport of lipoprotein particles in rat liver. J. Cell Biol., 64: 356377, 1975.

Goldfischer, S., Arias, I. M., Essner, E. and Novikoff, A. B. : Cytochemical and electron microscopic studies of rat liver with reduced capacity to transport conjugated bilirubin. J. Exp. Med., 115: 467-474, 1962.

Goodenough, D. A. and Revel, J. P. : A fine structural analysis of intercellular junctions in the mouse liver. J. Cell Biol., 45: 272-290, 1970.

Goodenough, D.A. and Revel, J.P.: The permeability of isolated and in situ mouse hepatic gap junctions studied with enzymatic tracers. J. Cell Biol., 50: 81-91, 1971.

Goodenough, D. A. and Stockenius, W.: The isoloation of mouse hepatocyte gap junctions. Preliminary chemical characterization and X-ray diffraction. J. Cell Biol., 54: 646-656, 1972.

Goshima, K.: Formation of nexuses and electronic transmission between myocardial and FL cells in monolayer culture. Exp. Cell Res., 63: 124-130, 1970.

Grubb, D. J. and Jones, A. L.: Ultrastructure of hepatic sinusoids in sheep. Anat. Rec., 170: 75-80, 1971.

Hamilton, R. L., Regan, D. M. and Lequire, V.S.: Electron microscopic studies of lipoprotein transport in the perfused rat liver. Fed. Proc., 25: 361, 1966.

Hardistry, M. W. and Potter, I.C.: The Biology' of Lampreys. Vol. 1, Academic Press, 1971.

Hardistry, M. W. and Potter, I.C.: The Biology of Lampreys. Vol. 2, Academic Press, 1972.

Heath, T. J. and Wissig, S. L.: Fine structure of the surface of mouse hepatic cells. 
Am. J. Anat., 119: 98-128, 1966,

Hirosawa, K. and Yamada, E.: The localization of the Vitamin A in the mouse liver as revealed by electron microscope autoradiography. J. Elect. Microsco., 22: 337-346, 1973.

Hruban, Z., Vigil, E. L., Slesers, A. and Hoplins, E.: Microbodies. Constituent organelles of animal cells. Lab. Invest., $27: 184-191,1972$.

Ito, T.: Recent advances in the study on the fine structure of the hepatic sinusoidal wall. Gunma Rep. Sci., 6: 119-163, 1973.

Ito, T. und Shibasaki, S.: Morphologische Untersuchungen über die Lunge bei der Fledermaus: Elektronenmikroskopische Beobachtungen der Alveolarwand. Arch. Histol. Jap., 25 : 491-531, 1965.

Ito, T. and Shibasaki, S.: Electron microscopic study on the hepatic sinusoidal wall and the fat storing cells in the normal humal liver. Arch. Histol. Jap., 29: 137-192, 1968.

Jatlow, P., Adams, W. R. and Handschmacher, R.E.: Pathogenesis of orotic acid induced fatty change in the rat liver. Light and electron microscopic studies. Am. J. Path., 47: 125-145, 1965.

Jones, A. L., Ruderman, N. B. and Herrera, M. G.: Electron microscopic and biochemical study of lipoprotein synthesis in the isolated perfused rat liver. J. Lipid Res., 8 : 429-446, 1967.

Karnovsky, M. J.: The ultrastructural basis of transcapillary exchanges. J. Gen. Physiol., 52: 64-95, 1968.

Karrer, H.F.: Electron microscope observations on chick embryo liver. J. Ultrastruct. Rec., 5 : 116-141, 1961.

Kobayashi, K. and Takahashi, Y.: Effect of the administration of large doses of Vitamin $A$ on the fine structure of rat liver with special reference to changes in the fat storing cell. Arch. Histol. Jap., 33: 421-443, 1971.

Kuhn, N.O. and Oliver, M.L.: Ultrastructure of the hepatic sinusoid of the goat Capra Hircus. J. Cell Biol., 26 : 977-979, 1965.

Lo, C. and Marsh, J. B.: Biosynthesis of plasma lipoproteins. Incorporation of $14 \mathrm{C}$ glucosamine by cells and subcellular fractions of rat liver. J. Biol. Chem., 245 : 5001-5006, 1970.

Lombardi, B.: Pathogenesis of fatty liver. Fed. Proc., 24: 1200-1205, 1965.

Lombardi, B.: Fatty liver. Consideration on the pathogenesis of fatty liver. Lab. Invest., 15: 1-20, 1965.

Muir, A.B.: The effect of divalent cations on the ultrastructure of the perfused rat heart. J. Anat., 101 : 239-261, 1967.

Novikoff, A.B., Beard, M.E., Albala, A., Sheid, B., Quintana, N. and Biempica, L.: Localization of endogeneous peroxidase in animal tissues. J. Microscopie, 12: 381-404, 1971.

Novikoff, A.B. and Essner, E.: The liver cell; Some new approaches to its study. Am. J. Med., 29: 102-131, 1960.

Novikoff, A.B. and Holtzman, E.: The Golgi apparatus (Chapter 2.5). Cells and Organelles, 90-98, 1970.

Novikoff, P.M. and Novikoff, A.B.: Peroxisomes in absorptive cells of mammalian small intestine. J. Cell Biol., 53 : 532. 560, 1972.

Novikoff, P.M., Novikoff, A.B., Quintana, N. and Adams, C.: Studies on microperoxisomes, III. Observations on human and rat hepatocytes. J. Histochem., 21: 540-558, 1973.

Novikoff, P. M., Novikoff, A. B., Quintana, N. and Hauw, J. J.: Golgi apparatus, GERL and lysosomes of neuron in rat dorsal root ganglia, studied by thick section and thin section cytochemistry. J. Cell Biol., 50: 859-886, 1971. 
Ogawa, K. and Abe, S.: Lysosome. Special issue, Intracellular Organelles (2), Iden, 27: 29-40, 1973 (in Japanese).

Orlandi, F.: Electron microscopic observations on human liver during cholestasis. Acta Hepato-splenol., $9:$ : 155-164, 1952.

Park, H.F.: Notes on membrane enclosed lipid spherules in hepatic cells of the mouse. Anat. Rec., 151: 397-398, 1965.

Payton, B.W., Bonnet, M. V.L. and Pappas, G.D.: Permeability and structure of junctional membranes at an electron synapse. Science (Wash. D.C.), 166: 1641$1643,1969$.

Peracchia, C.: Low resistance junctions in crayfish. II. Structural details and further evidence for intercellular channels by freeze fracture and negative staining. J. Cell Biol., 57: 66-76, 1973.

Roessle, R.: Entzündungen der Leber. In Handbuch der speziellen Pathologischen Anatomie und Histologie, Vol. 5, 1930.

Satsuki, S.: Experimentelle Untersuchungen über den Einfluss der Futterung auf die Leber und ihre Fettspeicherungszellen (Fat storing cell) bei Hungerkaninchen. Arch. Histol. Jap., 8 : 557-559, 1955.

Satsuki, S., Tsunoda, K. and Shindo, K.: Über das Verhalten der Leberzellen, Sternzellen und Fettspeicherungszellen (Fat storing cell) der Meerschweinchenleber gegenüber der intravenos verabreichten Fettemulsion. Arch. Histol. Jap., 9: 517-547, 1956.

Schaffner, F. and Popper, H.: Capillarization of hepatic sinusoids in man. Gastroenterology, $44: 239-242,1963$.

Schlunk, F.F. and Lombardi, B.: Liver liposomes. I. Isolation and chemical characterization. Lab. Invest., 17:30-38, 1967.

Sjöstrand, F.S. and Hanzon, V.: Ultrastructure of Golgi apparatus of exocrine cells of mouse pancreas. Exp. Cell. Res., 7: 393-414, 1954.

Smith, J.E., Muto, Y., Milch, P.O. and Goodman, D.S.: The effects of chylomicron vitamin $A$ on the metabolism of retinol binding protein in the rat. J. Biol. Chem., 248 : 1544-1549, 1973.

Stein, O. and Stein Y.: Lipid synthesis, intracellular transport, storage, and secretion. I. Electron microscopic radioautographic study of liver after injection of tritiated palmitate or glycerol in fasted and ethanol treated rats. J. Cell Biol., 33: 319-339, 1967.

Stenger, R.: Hepatic sinusoids in carbon tetrachloride-induced cirrhosis. Arch. Path., 81 : 439-447, 1966.

Sterling, J. A., Meranze, D. R., Einsten, S. and Krieger, M. K. : Observations of lamprey liver during its life cycle. J. Albert Einstein Med. Center, 15: 1957.

van Golde, L. M., Fleischer, B. and Fleischer, S.: Some studies on the metabolism of phospholipids in Golgi complex from bovine rat liver in comparison to other subcellular fractions. Biochem. Biophys. Acta, 249 : 318-330, 1971.

Wisse, E.: An electron microscopic study of the fenestrated endothelial lining of rat liver sinusoids. J. Ultrastruct. Res., 31: 125-150, 1970.

Wood, R.L.: Evidence of species differences in the ultrastructure of the hepatic sinusoid. Z. Zellforsch. Mikrosk. Anat., 58: 672-692, 1963.

Yamagishi, M.: Electron microscope studies on the fine structure of the sinusoidal wall and fat storing cells of rabbit livers. Arch. Histol. Jap., 18 : 223-261, 1959. 


\section{PLATES}




\section{Explanation of Figures \\ Plate I}

Fig. 1. The micrograph illustrates the portion of the ammocoetes liver showing lysosomes ( $\mathrm{L}$ ) around the bile canaliculus $(\mathrm{Bc}$ ) and mitochondria $(\mathrm{M})$ which distribute peripherally to the complexes of the RER cisternae. The intercellular space (Is) is saccular in appearance. The space (Hs) between the hepatocytic tubules, which are surrounded by the basement laminas, is somewhat straightened. The endothelial cell (E) and the fat storing cell (FSC) are observed. $\times 4,900$.

Fig. 2. The micrograph illustrates the portion of the ammocoetes liver showing two basement laminas within the space of Disse. Of these laminas, one beneath the endothelial cell is discontinuous $\left(B^{\prime \prime}\right)$ and the other surrounding the surface of the hepatocytes is continuous ( $\left.B^{\prime}\right)$. The gap junction $(G j)$ is observed. $\times 37,500$.

Fig. 3. The micrograph shows the fat storing cell (FSC) containing one lipid droplet in the ammocoetes liver. E: endothelium. $\times 14,000$. 
Plate I
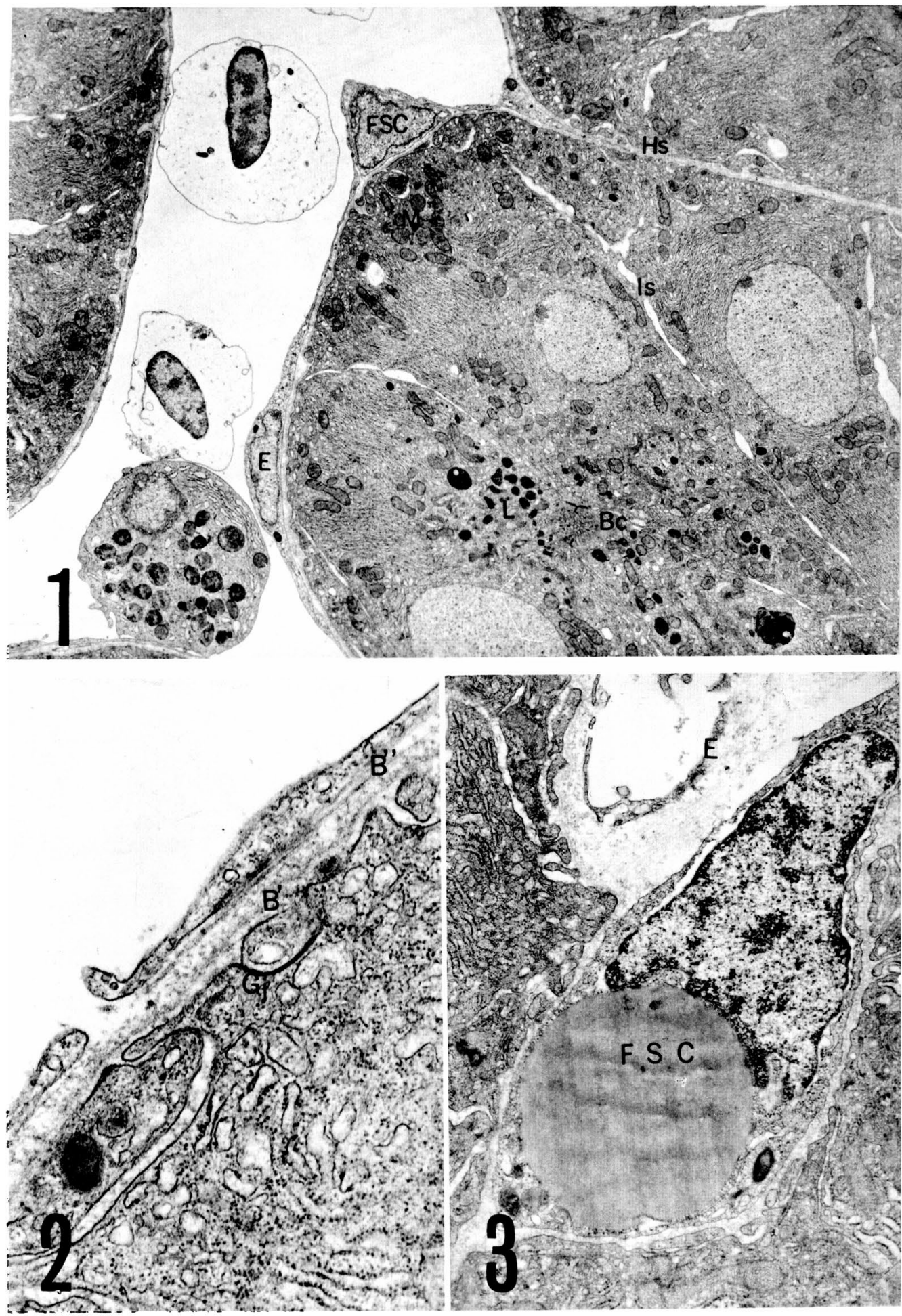


\section{Plate II}

Fig. 4. The micrograph illustrates the ammocoetes liver showing bile canaliculus (Bc) with numerous microvilli. The electron dense particles $(P)$ in the lumen of the bile canaliculus are somewhat resemble to the contents of the lysosomes (L) in density. The junctional complex (Jc) is also observed at the side of the bile canaliculus. Is: intercellular space. $\times 37,500$.

Fig. 5. The micrograph illustrates the ammocoetes hepatocyte showing parallel Golgi cisternae (G) with dilated ends which contain flocculent materials of low electron density. The vesicles, some of them are coated, are observed in the vicinity of the Golgi cisternae. The vacuoles (GV) contain finely granular materials of moderate electron density or closely packed materials of high electron density. The mitochondria (M) are found. Is : intercellular space. $\times 25,000$. 
Plate II
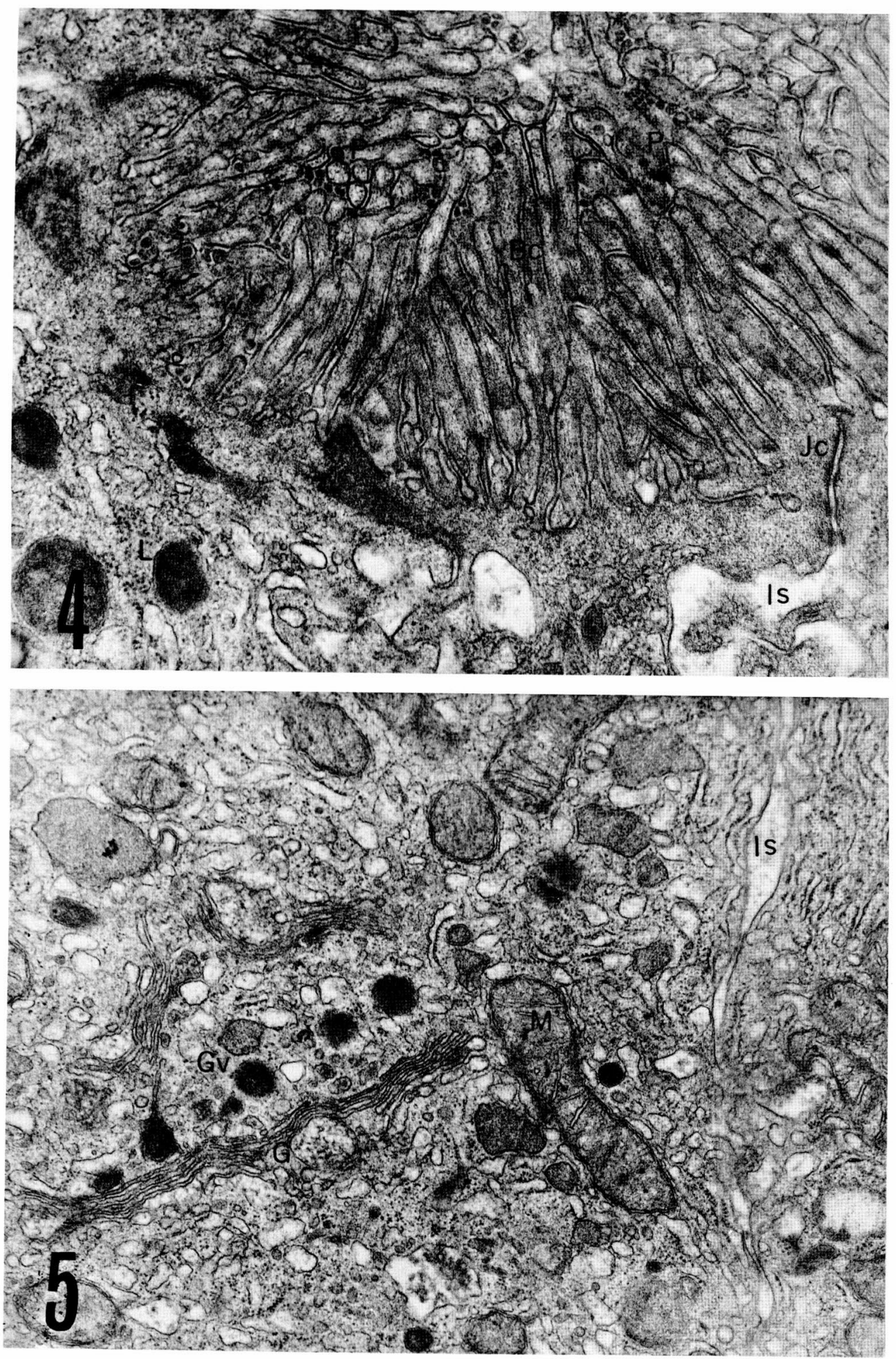


\section{Plate III}

Fig. 6. The micrograph illustrates the portion of the adult lamprey hepatocyte in the early stage of metamorphosis showing dilated Golgi cisternae (G) with numerous vesicles, some of them are coated ones. The electron dense granules which appear singly, clustered or as a row in the tubules or vesicles of the RER with flocculent materials of low electron density. A vesicle contains packed electron dense granules. The vacuoles $(V)$, whose limiting membranes are somewhat thickened, contain flocculent materials of low density. The lysosomes (L) and mitochondria (M) are observed. The lipid droplet $(\mathrm{Li})$ is also observed. The remnant of the bile canaliculus $(\mathrm{rBc})$ is observed between the apposed hepatocytes. $\times 24,500$.

Fig. 7. The micrograph illustrates the portion of the adult lamprey hepatocyte in the early stage of metamorphosis showing electron dense granules which appear clustered or as a row in the tubules without ribosomes (T). The vacuoles (V) with thickened limiting membranes contain flocculent materials of low electron density. The mitochondria (M) and lysosomes (L) are observed. One of the latters contains granular and amorphous materials of high electron density. $\times 24,500$. 







\section{Plate IV}

Fig. 8. The micrograph illustrates the portion of the adult lamprey liver in the late stage of metamorphosis showing hepatocytes which are widely separated each other. Each hepatocyte contains several lipid aroplets $(\mathrm{Li}) . \times 6,500$.

Fig. 9. The micrograph illustrates the portion of the adult lamprey liver in the late stage of metamorphosis showing fat storing cell (FSC) with Golgi complexes (G) which consist of parallel cisternae, vesicles and vacuoles. The vacuoles are lucent. The cisternae of the RER are scattered randomly throughout the cytoplasm. The free ribosomes are aggregated into small clusters. The lipid droplet $(\mathrm{Li})$ and mitochondria $(\mathrm{M})$ are observed. $\times 48,000$.

Fig. 10. The micrograph shows gap junction $(\mathrm{Gj})$ between the hepatocytes of the adult lamprey in the late stage of metamorphosis. $\mathrm{Li}$ : lipid droplet. Is : intercellular space. $\times 48,000$. 
Plate IV

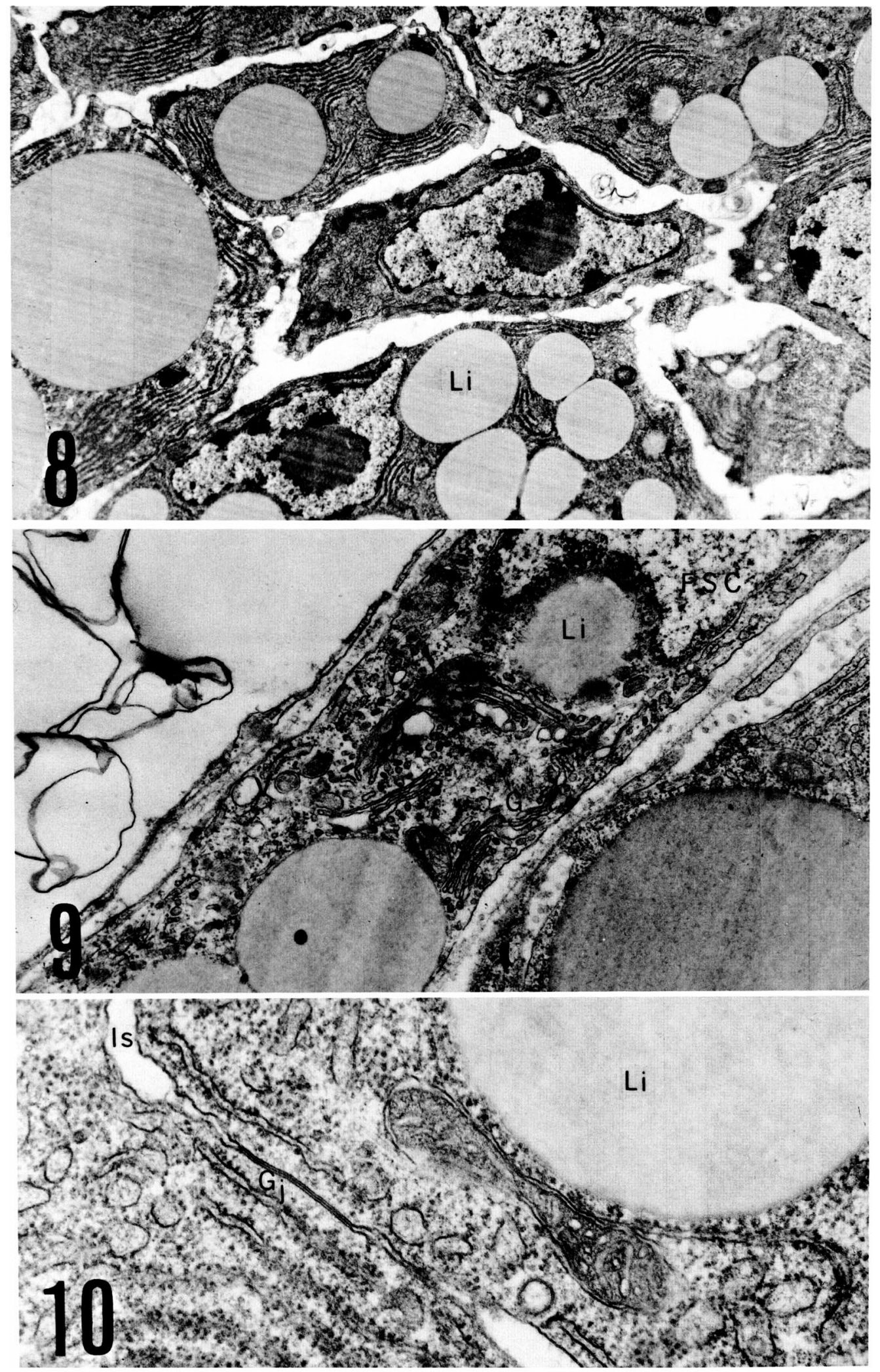




\section{Plate V}

Fig. 11. The micrograph illustrates the portion of the adult lamprey hepatocyte in the late stage of metamorphosis showing curved arrays of Golgi cisternae (G) with vesicles and vacuoles which contain packed flocculent materials of moderate density. The flocculent materials are also observed in the vacuoles (V) whose limiting membranes are somewhat thickened. The tubules without ribosomes $(\mathrm{T})$ contain electron dense granules with flocculent materials of moderate density. The granules are also observed in the tubules or vesicles of the RER. $\times 14,000$.

Fig. 12. The micrograph illustrates the portion of the adult lamprey hepatocyte in the late stage of metamorphosis showing curved arrays of Golgi cisternae (G) containing poorly discreted granules especially in their portions. The Golgi cisternae are partly disarranged as a whorl. The contents in the Golgi vacuoles are electron dense and amorphous. The cisternae of the RER are randomly distributed throughout the cytoplasm. The membrane of the smooth surfaced lamella (S) is connected with that of the RER. A portion of lipid droplet $(\mathrm{Li})$ is observed. $\times 25,000$. 


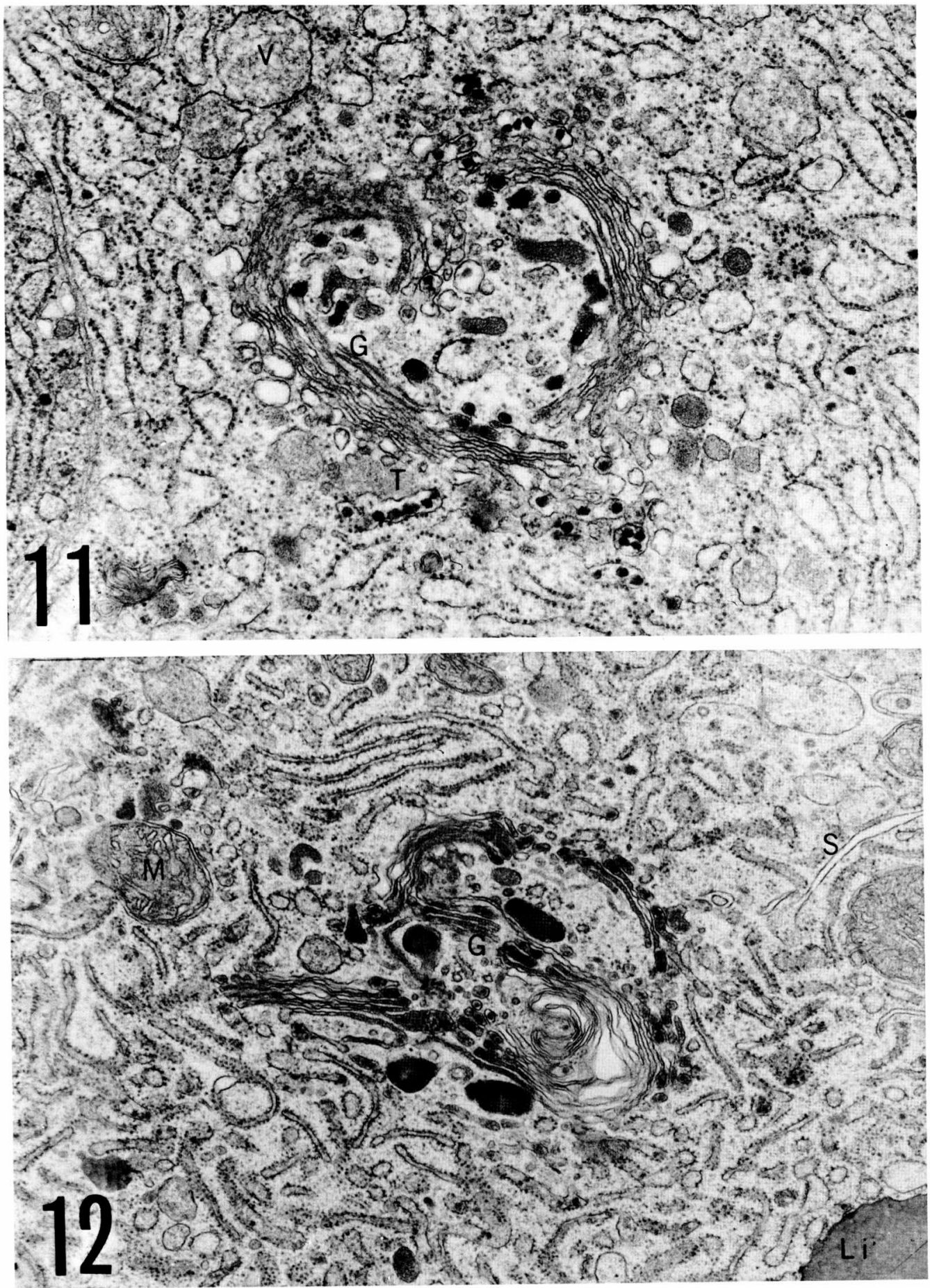




\section{Plate VI}

Fig. 13. The micrograph shows amorphous but mottling with electron dense materials which are surrounded by limiting membrane with a few attached ribosomes $(\mathrm{L} p)$ in the hepatocyte of the adult lamprey in the late stage of metamorphosis. Li: lipid droplets. $\mathrm{N}$ : nucleus. $\times 36,000$.

Fig. 14. The micrograph illustrates the portion of the adult lamprey hepatocyte in the late stage of metamorphosis showing liposomes ( $\mathrm{L} p$ ) which consist of amorphous dense materials surrounded by membranes with a few attached ribosomes. The amorphous electron dense materials are also found in the vesicles or tubules with or without ribosomes. The electron dense granules are observed not only in the vesicles or tubules of the RER but also in the nuclear envelope (arrow). The vacuoles (V), whose limiting membrane is somewhat thickened, contains flocculent materials of low electron density. $\mathrm{M}$ : mitochondria. $\mathrm{N}$ : nucleus. $\times 36,000$.

Fig. 15. The micrograph illustrates the portion of the adult lamprey hepotocyte in the late stage of metamorphosis showing giant liposome ( $\mathrm{gLp}$ ) which consist of the limiting membrane with attached ribosomes surrounding the amorphous electron dense material similar to that of the lipid droplet $(\mathrm{Li}) . \times 55,000$. 

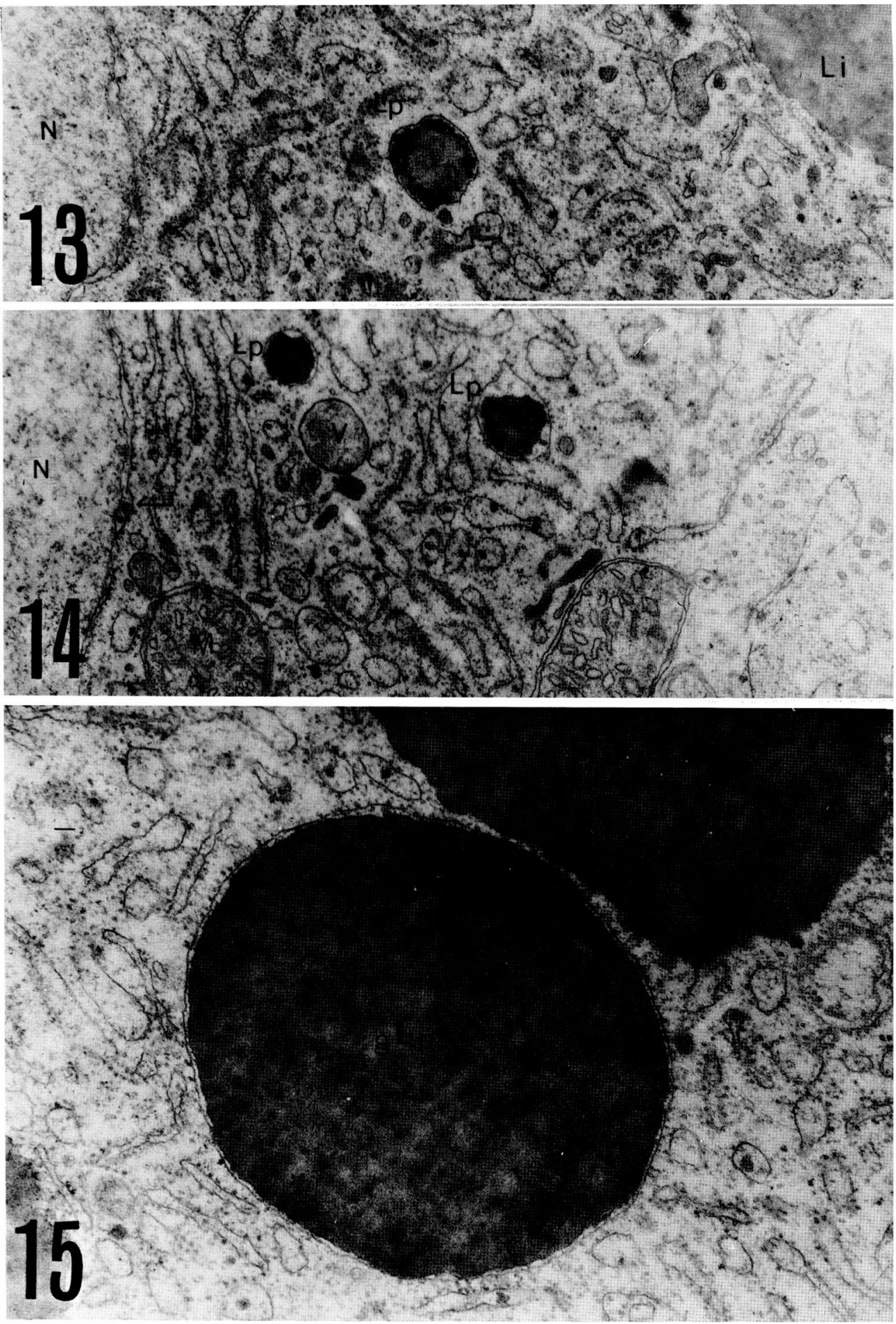


\section{Plate VII}

Fig. 16. The micrograph shows lysosomes with or without deposits of acid phosphatase reaction products. $\mathrm{N}$ : nucleus. $\times 14,000$.

Fig. 17. The micrograph illustrates the lysosomes showing strong reactions for the peroxidase activities. $\mathrm{N}$ : nucleus. $\times 19,000$. 
Plate VII
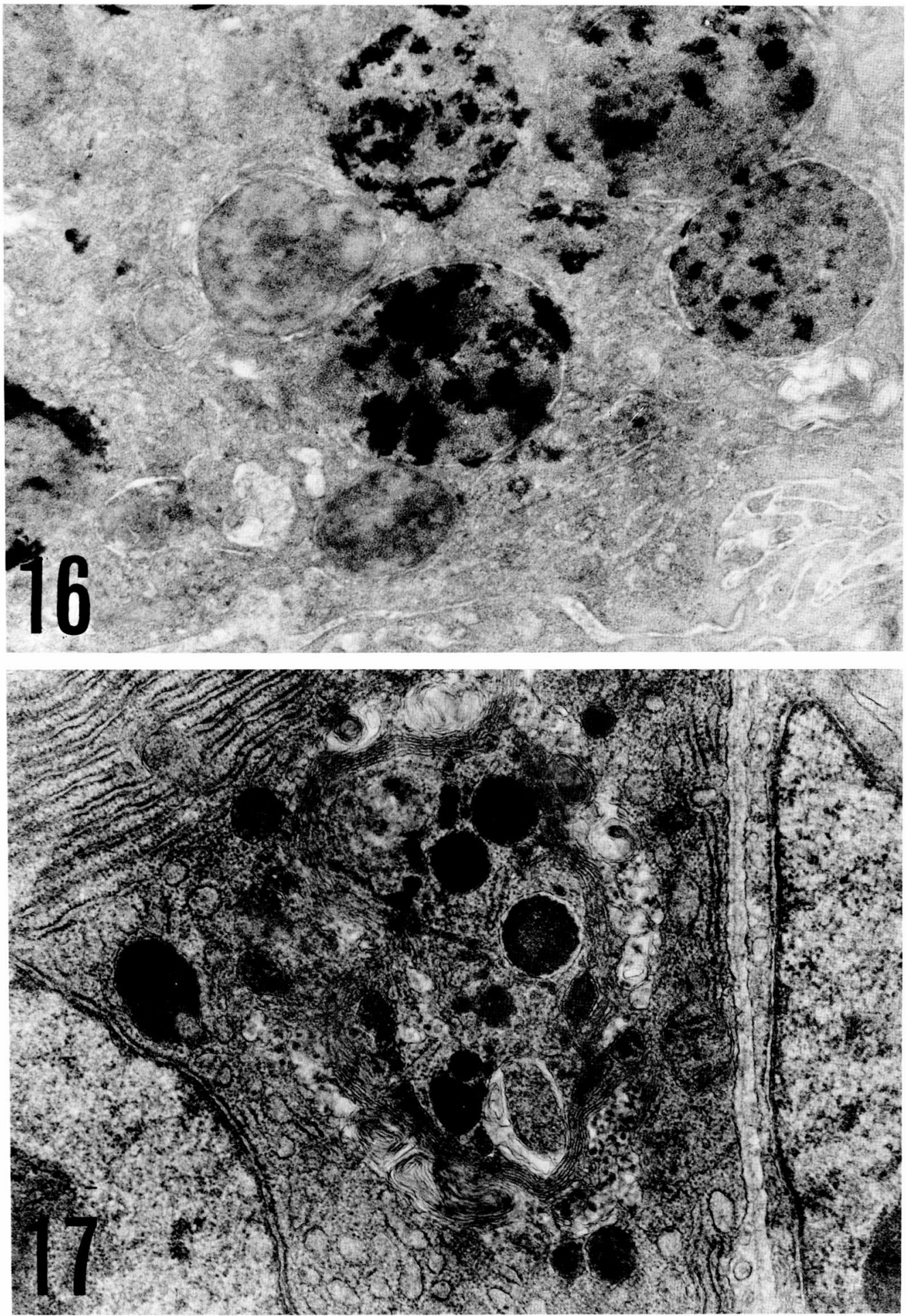